\title{
The effect of insulin receptor deletion in neuropeptide $Y$ neurons on hippocampal dependent cognitive function in aging mice
}

\author{
Elisabeth K. Goodman ${ }^{1}$, Caitlin S. Mitchell ${ }^{1}$, Jonathan D. Teo ${ }^{1}$, Joanne M. Gladding ${ }^{1}$, Kirsten N. Abbott ${ }^{1}$, Neda Rafiei $^{1}$, \\ Lei Zhang ${ }^{2}$, Herbert Herzog ${ }^{2}$, Denovan P. Begg ${ }^{1, *}$ \\ ${ }^{1}$ School of Psychology, UNSW Sydney, 2052 Sydney, Australia \\ ${ }^{2}$ Garvan Institute of Medical Research, 2010 Darlinghurst, Australia \\ *Correspondence: d.begg@unsw.edu.au (Denovan P. Begg)
}

DOI:10.31083/j.jin2101006

This is an open access article under the CC BY 4.0 license (https://creativecommons.org/licenses/by/4.0/).

Submitted: 29 April 2021 Revised: 29 July 2021 Accepted: 27 August 2021 Published: 28 January 2022

Insulin is known to act in the central nervous system to regulate several physiological and behavioural outcomes, including energy balance, glucose homeostasis and cognitive functioning. However, the neuronal populations through which insulin enhances cognitive performance remain unidentified. Insulin receptors are found in neuropeptide-Y (NPY) expressing neurons, which are abundant in the hypothalamus and hippocampus; regions involved in feeding behaviour and spatial memory, respectively. Here we show that mice with a tissue specific knockout of insulin receptors in NPY expressing neurons $\left(\mathrm{IR}^{l o x / l o x} ; \mathrm{NPY}^{C r e /+}\right)$ display an impaired performance in the probe trial of the Morris Water Maze compared with control mice at both the 6 and the 12, but not at the 24 months time point, consistent with a crucial role of insulin and NPY in cognitive functioning. By 24 months of age all groups demonstrated similar reductions in spatial memory performance. Together, these data suggest that the mechanisms through which insulin influences cognitive functioning are, at least in part, via insulin receptor signaling in NPY expressing neurons. These results also highlight that cognitive impairments observed in aging may be due to impaired insulin signaling.

\section{Keywords}

Insulin receptors; NPY; Spatial memory; Hippocampus; Morris Water Maze

\section{Introduction}

Insulin signaling occurs when insulin activates the insulin receptor (IR), this ultimately results in glucose uptake by the cell. The process is orchestrated by intracellular signalling, including the phosphoinositide 3-kinase (PI3K) pathway and the phosphorylation of Akt/protein kinase B [1]. Insulin signaling within the brain plays important roles in cognition, learning and memory. When insulin signaling becomes dysregulated, such as in the case of insulin resistance and longterm compensatory elevations of circulating insulin, an increased risk for developing cognitive pathologies occur, such as Alzheimer's disease [2]. The link between insulin resistance and cognition is shown in rodent studies which use the Morris Water Maze (MWM), a task used to evaluate spatial learning and memory [3]. Animals that present with insulin resistance have reduced performance in the MWM [4-12]. These deficits can be ameliorated by central insulin infusion, which can increase performance in the memory component of the MWM [13].

Within the central nervous system (CNS), the hippocampus, an area responsible for memory and learning, is a prominent target for insulin signaling. A high density of IRs within the dorsal hippocampus suggests a role for insulin in the formation of spatial memory $[14,15]$. In support, CA1 hippocampal insulin administration enhanced memory consolidation and retrieval in the MWM, which is considered to specifically test for hippocampal-dependent cognitive deficits. This suggests that insulin directly regulates memory by acting on the hippocampus $[14,16]$. Using a lentiviral vector to downregulate IRs in the rat hippocampus, Grillo and colleagues demonstrated that hippocampal insulin resistance results in deficits in hippocampal synaptic transmission and hippocampal-dependent learning [17]. Importantly, these deficits were seen to be independent of metabolic or endocrine imbalances. This study provides important evidence that hippocampal insulin signaling facilitates neuroplasticity and cognition [17].

Insulin signaling within the CNS declines with age and insulin resistance is a risk factor for age-related Alzheimer's disease and cognitive decline [18]. With aging, a marked decrease in glucose transporters [19], insulin receptors [20], insulin levels [21] and insulin signaling [22] have all been observed, which has been linked to age related hippocampal memory impairments [23]. However, central insulin resistance and aging do not always go hand-in-hand, with factors such as body composition, lifestyle and exercise having important influences. Notably, central and peripheral insulin resistance do not always occur concurrently, as dysregulated CNS insulin signaling can precede, or help initiate, the onset of peripheral insulin resistance [24].

As well as aging, sex can also influence insulin signaling within the CNS. Male rats have increased anorexigenic 
sensitivity to insulin infusion compared to female rats [25], while acute intranasal insulin in female patients improved hippocampal-dependent memory, whereas males did not show an enhancement [26]. Another study examined individuals with mild cognitive impairments and demonstrated that men show an improvement in working memory after intranasal insulin, but only at a dose twice as high as shown to be effective in women [27]. Some of these sex differences appear to be the result of differential gonadal hormone levels [28]. Overall, a strong link between intra-hippocampal insulin signaling and cognitive performance has been identified, however, the specific neuronal population mediating these effects within the hippocampus has not yet been identified.

Neuropeptide-Y (NPY), a 36-amino acid peptide, is abundantly expressed throughout the brain, including the hippocampus [29]. NPY is involved in the regulation of biological and pathophysiological functions including feeding behaviours, neuroplasticity, memory and learning [30]. NPY has a modulatory role in spatial memory and learning as it appears to exercise both stimulatory and inhibitory effects on memory, contingent on the NPY receptor subtype manipulated, dose applied, neuroanatomical brain systems involved, temporal step (i.e., retrieval, acquisition, retention, consolidation) and memory type [31-34]. Hippocampal NPY has been associated with spatial learning and memory during the MWM, as increased levels of NPY mRNA were observed in the dentate gyrus of the hippocampus following MWM exposure [35]. Further, brains from Alzheimer's patients show loss of NPY-positive neurons in the hippocampus [36], while NPY injections into the dorsal hippocampus increases memory retention in mice [37]. Altogether, these data show that NPY and insulin signaling play important roles for learning and memory by signaling within the hippocampus.

To date, it is unknown how disruption of insulin signaling in NPY expressing neurons affects performance in hippocampal dependent cognitive tasks, such as the MWM. To address this, we utilised the Cre-lox recombination technique in mice to selectively knock out IRs in NPY expressing neurons ( $\left.\mathrm{IR}^{l o x / l o x} ; \mathrm{NPY} C r e /+\right)$. Mice were tested in the MWM at 6,12 and 24 months of age to assess how aging influences behavioural deficits induced by ablated IRs on NPY neurons.

\section{Materials and methods}

\subsection{Animals}

A conditional knockout mouse model was generated to selectively knockout the IR in NPY expressing neurons $\left(\mathrm{IR}^{l o x / l o x} ; \mathrm{NPY} C r e /+\right)$. This mouse model has been validated in previous work, which functionally demonstrated that IRs were deleted from NPY neurons [38]. To generate this conditional knockout, Floxed IR mice $\left(\mathrm{IR}^{\text {lox } / l o x}\right)$ [39] were crossed with NPYCre/+ mice [40] to generate double heterozygous mice; $\mathrm{IR}^{l o x /+} ; \mathrm{NPY} C r e /+$. These mice were then crossed again with $\mathrm{IR}^{l o x / l o x}$ mice to generate $\mathrm{IR}^{\text {lox } / \text { lox }} ; \mathrm{NPY} C r e /+$ mice. Breeding colonies were main- tained by mating $\mathrm{IR}^{\text {lox/lox }}$ mice with $\mathrm{NPY} C r e /+; \mathrm{IR}^{\text {lox } / \text { lox }}$ mice. All mice were bred on a $\mathrm{C} 57 \mathrm{Bl} / 6 \mathrm{~J}$ background.

Littermates that lacked the Cre recombinase enzyme $\left(\mathrm{IR}^{l o x / l o x}\right)$ were used as controls as they express normal IR signaling within NPY-expressing neurons [38]. This mouse line was maintained at Australian BioResources Ltd, Moss Vale, NSW, Australia, with genotyping also being performed at this facility. For behavioural studies, 56 $\mathrm{IR}^{\text {lox/lox }}$;NPYCre/+ (28 females and 28 males) and 59 $\mathrm{IR}^{\text {lox/lox }}$ control mice (30 females and 29 males) were tested at 6 and 12 months of age. Due to age-related health issues of some mice, $52 \mathrm{IR}^{\text {lox } / \text { lox }} ; \mathrm{NPY}$ Cre/+ (26 females and 26 males) and $54 \mathrm{IR}^{\text {lox/lox }}$ control mice (28 females and 26 males) were tested at 24 months of age. An additional 20 male mice were used for immunohistochemistry analysis (10 mice/genotype, 6 months of age). Mice were housed two to four per cage $(37 \times 23 \times 14 \mathrm{~cm})$ under temperaturecontrolled conditions $\left(22 \pm 2{ }^{\circ} \mathrm{C}\right)$ with a 12 hour light-dark cycle (07:00 on-19:00 off). Upon arrival, mice were handled and allowed to become acclimated to their new environment. For the duration of the experiment, unless otherwise specified mice were provided ad libitum access to water and standard laboratory chow from a home cage dispenser. Body weights and food intakes were measured one week prior to the commencement of each behavioural testing time point using a manual averaging balance. Energy intake was calculated based on the quantity of food consumed and the known caloric density of the standard chow diet.

Experimental procedures were approved by the University of New South Wales Animal Care and Ethics Committee in accordance with the Australian Code of Practice and Use of Animals for Scientific Purposes. Nine animals were euthanised between 12 and 24 months due to health issues ( 4 female, 5 male). These animals were included in the data analysis for earlier timepoints.

\subsection{Morris Water Maze}

The protocol used for training and testing in the MWM is based on established methods [13, 41]. Mice were trained to use distal spatial cues surrounding the maze to locate a hidden escape platform situated beneath the surface of the water. The water was kept at 22 degrees Celsius and rendered opaque by the addition of a non-toxic tempera powder. On Day 1 the escape platform was colored with black and white stripes and was raised $5 \mathrm{~mm}$ above the water level. $60 \mathrm{sec}$ onds was allowed for the mouse to locate the escape platform. Mice were gently guided onto the platform if they did not locate the platform in the allocated time. The mouse was allowed to remain on the platform for 15 seconds before being relocated to its home cage. This procedure was repeated for two trials with a 5 minute inter-trial period. From Days 2-4 the escape platform was positioned at the centre of the NW quadrant. Each mouse received four trials per day over three consecutive days with an inter-trial interval of 5 minutes. Each trial involved the release of the mouse from one of four fixed points (N, S, E, W), the starting quadrant positions. 
A

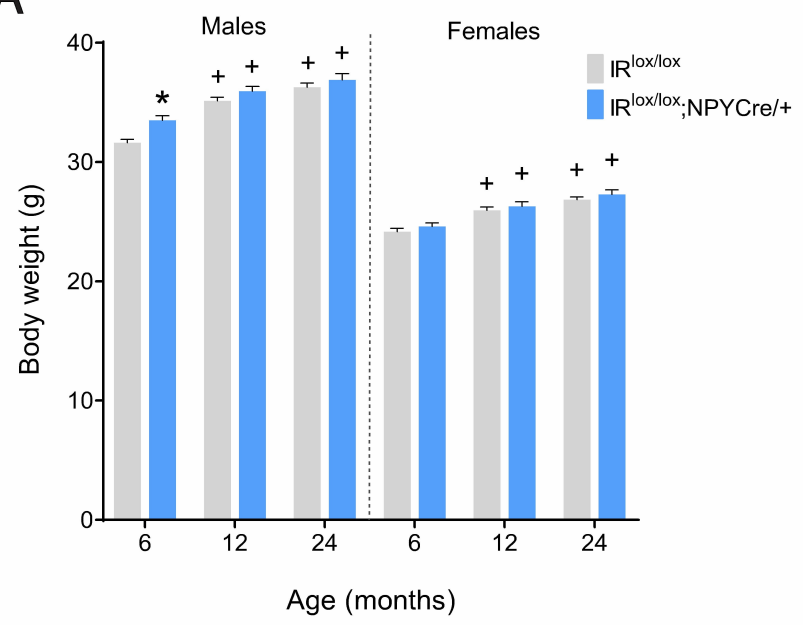

B

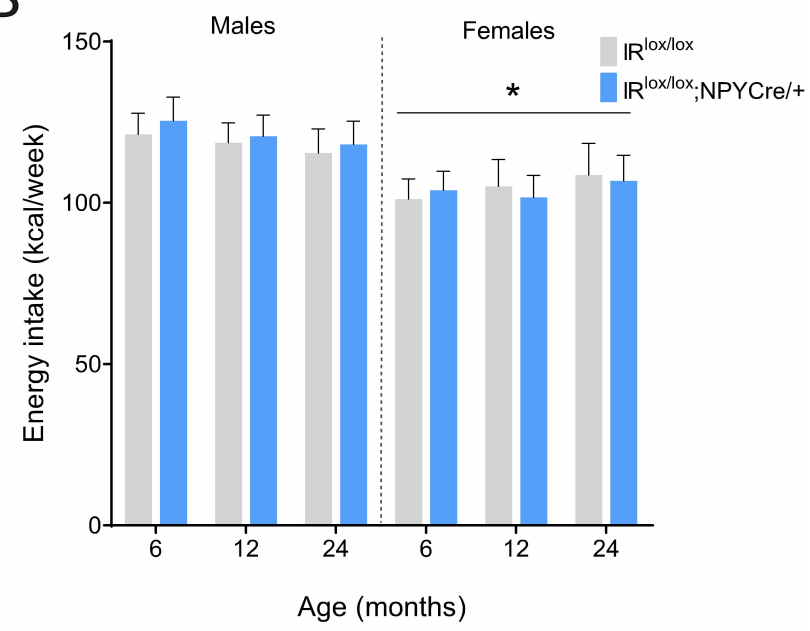

Fig. 1. Body weight and energy intake. (A) $\mathrm{IR}^{l o x} /$ lox $; \mathrm{NPY} C r e /+$ and littermate control mice (IR ${ }^{l o x} /$ lox $)$ gained weight over time. Male $\mathrm{IR}^{l o x / l o x} ; \mathrm{NPY} C r e /+$ mice displayed significantly increased body weight compared to male $\mathrm{IR}^{\text {lox } / \text { lox }}$ mice at 6 months of age. No differences in body weight between genotypes were observed at 12 or 24 months of age. Female mice did not show any body weight differences between genotypes at any time points. (B) Female mice displayed overall lower energy intake than male mice, however energy intake at 6,12 , or 24 months did not differ between genotypes. Values are expressed as mean \pm SEM. ${ }^{*}=$ interaction effect between $\mathrm{IR}^{l o x} /$ lox and $\mathrm{IR}^{l o x} /$ lox $; \mathrm{NPY}^{C r e} /+$ genotypes, $p<0.05 .+=$ main effect of time, $p<$ 0.05 . Analysed by 2-way ANOVA followed by Tukey's honest significance difference (HSD) test. 6 and $12 \mathrm{months}, \mathrm{n}=59 \mathrm{IR}{ }^{\text {lox }} /$ lox $(30 \mathrm{~F}$ and $29 \mathrm{M}$ ) and 56 $\mathrm{IR}^{\text {lox } / l o x} ; \mathrm{NPY} C r e /+(28 \mathrm{~F}$ and $28 \mathrm{M}) .24$ months, $\mathrm{n}=54 \mathrm{IR}^{\text {lox } / l o x}(28 \mathrm{~F}$ and $26 \mathrm{M})$ and $52 \mathrm{IR}^{\text {lox } / l o x} ; \mathrm{NPY}$ Cre/+ $(26 \mathrm{~F}$ and $26 \mathrm{M})$.

The starting positions were assigned in random order to prevent the use of a praxis strategy (using a learned sequence of movements), rather than a spatial mapping strategy and data from the four daily trials were averaged each day. Mice were dried and warmed after each training trial. Mice were allowed 60 seconds to locate the escape platform which was covered in white tape and submerged $5 \mathrm{~mm}$ below the surface. Mice were guided to the platform location if they failed to locate it in the allocated time. The mouse remained on the platform for 15 seconds before being placed back into the tank at one of the other four start positions. This was continued until the mouse had been allowed to find the submerged platform from all four quadrants. On Day 5 the 90 second probe trial was performed where the platform was removed. The time spent in the target quadrant and path length in the probe trial were scored using EthoVision (Noldus Information Technology, XT v5.1, Wageningen, The Netherlands). The position of the coordinates and cues were changed during testing at 12 and 24 months of age.

\subsection{Glucose Tolerance Test (GTT) and Insulin Tolerance Test (ITT)}

The GTT and ITT were conducted in mice following the completion of behavioural testing at 24 months of age. GTT: Following a 4 - $\mathrm{h}$ fast, the tip of the tail was cut $(\sim 1 \mathrm{~mm})$ and baseline glucose measured $(\sim 5 \mu \mathrm{L})$ (Accu-Chec; Roche Diagnostics, IN, USA) and $50 \mu \mathrm{L}$ blood collected for insulin measurement by ELISA (Crystal Chem, IL, USA). Mice were injected intraperitoneally with a glucose solution $(\sim 200$ $\mu \mathrm{L} /$ mouse; $1 \mathrm{~g} / \mathrm{kg}$ ). Blood glucose was assessed again at 15 , 30,60 and 120 minutes post injection and blood collected for insulin was evaluated again at 15 minutes. ITT: For the ITT, an insulin bolus ( $1 \mathrm{U} / 1 \mathrm{~kg}$ body weight) was administered via intraperitoneal injection. Blood glucose was assessed from 5 $\mathrm{uL}$ blood at 15, 30, 45 and 60 minutes post injection.

\subsection{Immunohistochemistry}

10 experimentally naive mice per genotype were injected with insulin (20 IU/kg, i.p) or saline (i.p; 5 animals per treatment group). After 20 minutes mice were anaesthetized with an overdose injection of sodium pentobarbitone $(120 \mathrm{mg} / \mathrm{kg}$, i.p), and the brains were fixed by perfusion with $0.9 \%$ saline followed by ice cold $4 \%$ paraformaldehyde made in $0.1 \mathrm{M}$ phosphate buffered saline (PBS) ( $\mathrm{pH} 7.4$ ). The brains were immediately removed and post-fixed in $4 \%$ paraformaldehyde overnight at $4{ }^{\circ} \mathrm{C}$ and then in $30 \%$ sucrose solution in phosphate buffer overnight. Coronal slices of $40 \mu \mathrm{m}$ thickness were collected and stored at $-20{ }^{\circ} \mathrm{C}$ in cryoprotectant (25\% ethylene glycol, 25\% glycerol, 50\% distilled water). Three sections per animal were used for immunohistochemistry. Sections were washed with PBS $+0.1 \%$ Tween 20 , incubated in sodium citrate antigen retrieval buffer (10 $\mathrm{mM}, \mathrm{pH} 6.0,70{ }^{\circ} \mathrm{C}, 10$ minutes) and blocked for 1 hour using 5\% normal goat serum (Vector labs, S-1000, Burlingame, CA, USA), $0.1 \%$ triton $\mathrm{x}-100$ and $0.1 \%$ bovine serum albumin (BSA) in PBS. Immediately following this, sections were incubated overnight at room temperature with the primary antibody, which was rabbit anti-phospho-Akt (1:2000 dilution, Cell Signaling Technology, 4060S, Danvers, MA, USA). Phosphorylated Akt (p-Akt) is a marker of insulin signaling pathway activation [42, 43]. After three washes in PBS $+0.1 \%$ Tween 20 , sections were incubated overnight 
A
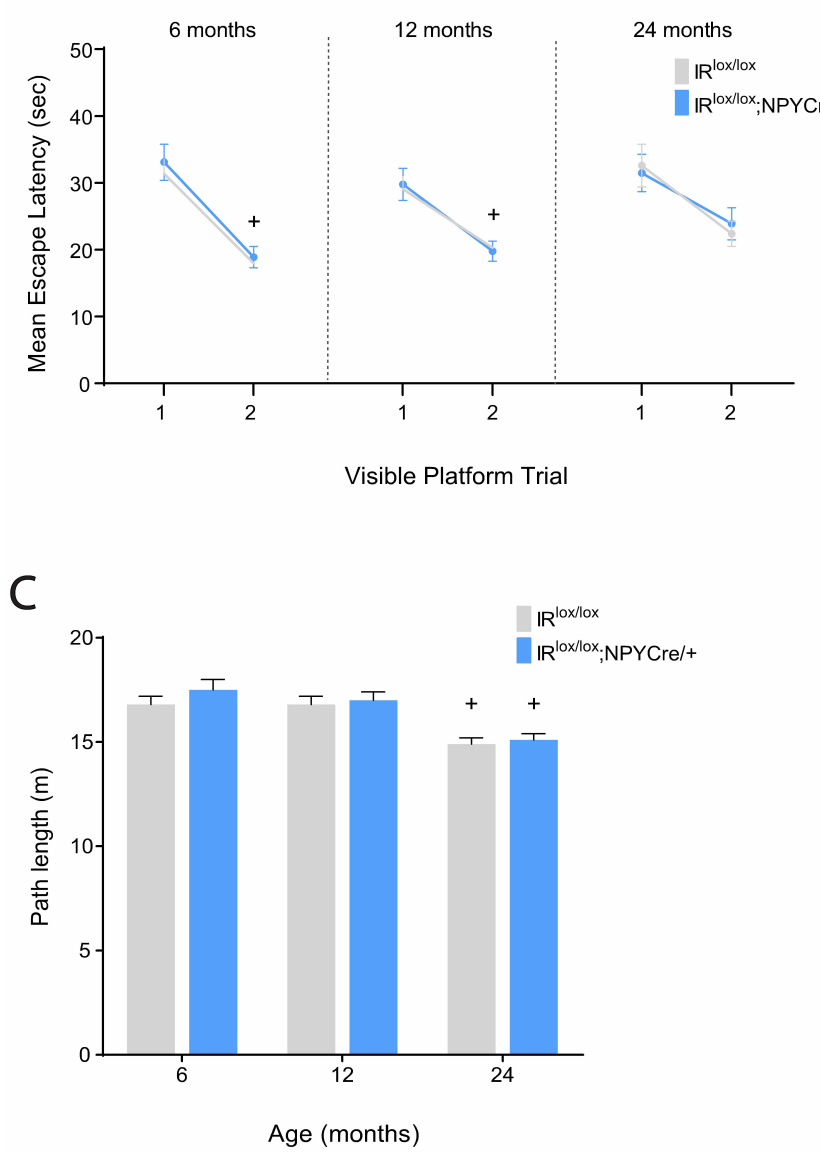

B

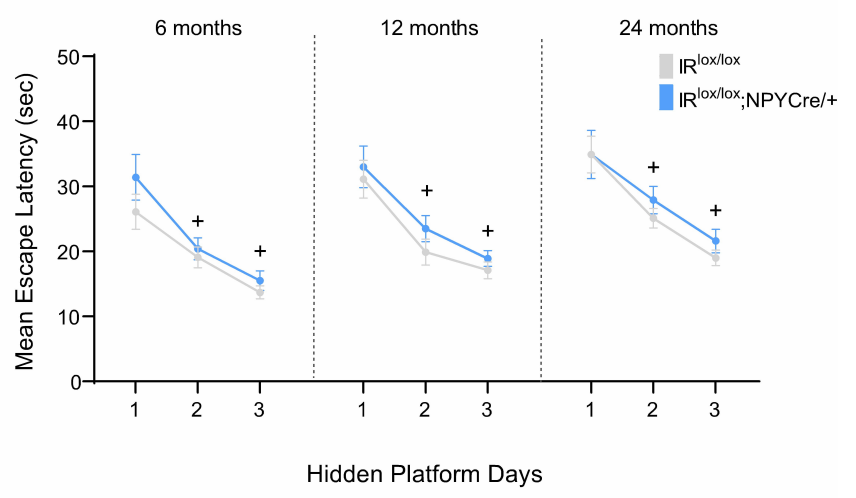

$\mathrm{D}$

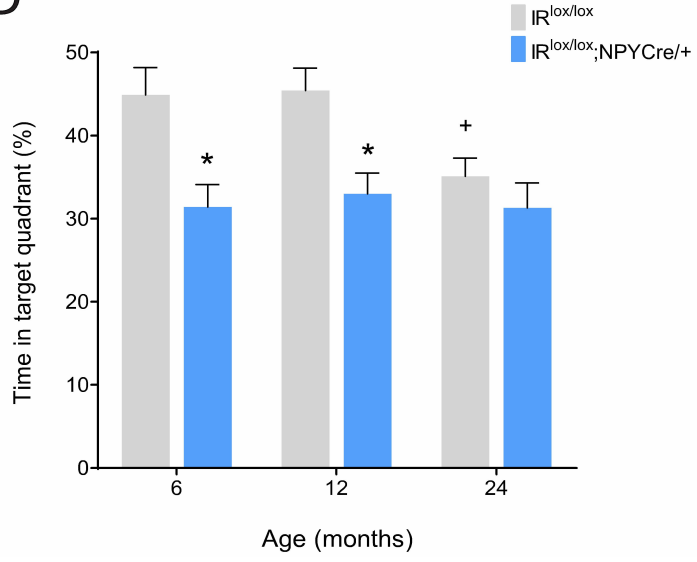

Fig. 2. Morris Water Maze performance. Mean escape latencies were collected for each trial day to assess performance over time. Time spent in the target quadrant was measured to assess hippocampal-dependent memory. (A) Mean escape latencies did not differ between IR ${ }^{l o x} /$ lox ${ }^{\mathrm{NPP}} \mathrm{Cre} /+{ }_{\text {and }}$ however, were significantly reduced on Day 2 for mice aged 6 and 12 months. At 24 months of age, no significant difference in mean escape latency was observed between Day 1 and Day 2. (B) Both $\mathrm{IR}^{l o x / l o x}$;NPYCre/+ and $\mathrm{IR}^{l o x / l o x}$ groups reached the platform faster across the hidden platform days at 6,12 and 24 months of age. (C) Both groups swam similar path lengths in the target quadrant during the probe trials. At 24 months, a decline in path length was exhibited in both $\mathrm{IR}^{l o x / l o x} ; \mathrm{NPY} C r e /+$ and $\mathrm{IR}^{l o x} /$ lox mice when compared over time to 6 and 12 month time points. (D) At 6 and 12 months of age, $\mathrm{IR}^{l o x / l o x} ; \mathrm{NPY} C r e /+$ mice spent significantly less time in the target quadrants compared to IR ${ }^{l o x} /$ lox control mice. At 24 months of age, no differences between genotypes was apparent. A main effect of age was seen at 24 months of age, with $\mathrm{IR}^{l o x / l o x}$;NPYCre/+ mice spending less time in the target quadrant compared to performance at 6 or 12 months of age. Values are expressed as mean \pm SEM. * $=$ interaction effect between IR ${ }^{l o x} / l o x$ and IR ${ }^{l o x} /$ lox $;$ NPY $C r e /+$ genotypes, $p<0.05 .{ }^{+}=$main effect of time, $p<0.05$. Analysed by 2 -way ANOVA followed by Tukey's honest significance difference (HSD) test. 6 and 12 months, $\mathrm{n}=59 \mathrm{IR}^{\text {lox } / l o x}$ and $56 \mathrm{IR}^{\text {lox } / \text { lox }} ; \mathrm{NPY}$ Cre/+. 24 months, $\mathrm{n}=54 \mathrm{IR}^{\text {lox } / \text { lox }}$ and $52 \mathrm{IR}^{\text {lox } / \text { lox }} ; \mathrm{NPY}$ Cre/+.

at room temperature with a fluorescent secondary antibody (1:1000 Goat anti-Rabbit IgG $(\mathrm{H}+\mathrm{L})$ secondary antibody, Alexa Fluor ${ }^{\circledR} 488$ conjugate ThermoFisher Scientific, A11034, NSW, Australia). All antibodies were diluted in antibody solution (5\% normal goat serum, $0.1 \%$ Triton X-100, $0.1 \%$ BSA, in PBS). Sections were washed once in PBS $+0.1 \%$ Tween 20 before being counterstained in DAPI solution (5 $\mathrm{mg} / \mathrm{mL}$, ThermoFisher Scientific, D3571, NSW, Australia) for 5 minutes. Sections then were washed again in PBS + $0.1 \%$ Tween 20 , mounted onto $0.1 \%$ gelatinized glass slides and coverslipped with ProLong Diamond antifade (ThermoFisher Scientific, P36961, NSW, Australia). Sections were visualized for $\mathrm{p}$-Akt within the brain nuclei of interest which were defined according to the mouse brain atlas (Franklin and
Paxinos [44]), using an Olympus FV1200 confocal microscope (Olympus, Tokyo, Japan). Using ImageJ software (version 1.47, LOCI, University of Wisconsin, Madison, Wisconsin, USA), the number of fluorescently labelled p-Akt cells in the dentate gyrus were counted by one experimenter, blinded, for all animals. The mean cell counts for each treatment group were then made into a percentage relative to mean cell counts from the control treatment group (IR ${ }^{l o x / l o x}$ + saline group).

\subsection{Statistical analysis}

The study employed a $2 \times 3$ between/within subjects design with the between level being genotype ( $\mathrm{IR}^{\text {lox/lox }}$, $\left.\mathrm{IR}^{l o x / l o x} ; \mathrm{NPY} C r e /+\right)$ and the within factor was age (6 months, 12 months, 24 months old). Data were analyzed 
using Statistica 12.0 (Dell Software, NSW, Australia) and is presented as means with standard errors. Data were first tested for normality and repeated measures (body weight and food intake) and 2-way between group ANOVAs (Behavioral tests) were followed by Tukey's honest significance difference (HSD) test for post-hoc analysis when a significant interaction effect was observed. Differences were accepted as statistically significant at $p<0.05$. Immunohistochemical analysis was performed using a 1-way ANOVA followed by Tukey's HSD test.

\section{Results}

3.1 Body weight and food intake

Male $\mathrm{IR}^{\text {lox/lox }} ; \mathrm{NPY}$ Cre/+ weighed significantly more than Male $\mathrm{IR}^{l o x / l o x}$ mice at 6 months $(p<0.05)$ but not at 12 or 24 months of age. There were no weight differences between genotypes in female mice at any age. Increased body weight was observed in both male and female mice with aging from 6 months to 12 and 24 months (Fig. $1 \mathrm{~A}, p<0.05$ ). There was a main effect of sex on food intake, with male mice consuming more than female mice (Fig. $1 \mathrm{~B}, p<0.05$ ).

\subsection{Morris Water Maze}

There were no significant differences observed between male and female mice across genotype and time points during MWM testing, therefore the data for both sexes have been combined for all of the following results. Both $\mathrm{IR}^{\text {lox/lox }} ; \mathrm{NPY} C r e /+$ and $\mathrm{IR}^{\text {lox } / \text { lox }}$ genotypes demonstrated similar escape latencies on Day 1 with improvements observed from the first to the second Visible Platform Trial at 6 and 12 months of age (Fig. 2A; $p<0.05$ ). Similarly, both groups began to reach the platform faster over the hidden platform training days at all ages (Fig. $2 \mathrm{~B}$; $p<0.05$ ), indicating that there were no learning performance impairments across the groups.

During the probe test, both groups swam similar path lengths until 24 months when both groups had reduced path length (Fig. 2C; $p<0.05$ ). These data suggest that differences between genotypes were not due to sensorimotor or motivational deficits. $\mathrm{IR}^{l o x / l o x} ; \mathrm{NPY} C r e /+$ mice spent less time in the target quadrant compared with control ( $\left.\mathrm{IR}^{\text {lox/lox }}\right)$ mice at 6 and 12 months. By 24 months both groups had reduced spatial performance with no differences between genotypes (Fig. 2D; $p<0.05$ ).

\subsection{Glucose tolerance and insulin sensitivity}

To rule out differences in peripheral glucose metabolism in $\mathrm{IR}^{\text {lox/lox }} ; \mathrm{NPY}$ Cre/+ mice, glucose tolerance and insulin sensitivity were examined. Both groups displayed a similar reduction in blood glucose after peripheral glucose injection $(p>0.05$, Fig. 3B) and peripheral insulin injection $(p>0.05$, Fig. 3A). Similarly, both genotypes displayed similar insulin release following glucose injection ( $p>0.05$, Fig. $3 \mathrm{C})$.

\subsection{Hippocampal p-Akt}

Peripheral insulin injection $(20 \mathrm{IU} / \mathrm{kg}$ ), compared to an i.p injection of saline, resulted in an increase of phospho- rylated Akt in the dentate gyrus of the hippocampus in $\mathrm{IR}^{\text {lox } / \text { lox }}$ animals (Fig. 4A,B). Phosphorylation of Akt was reduced in $\mathrm{IR}^{l o x / l o x} ; \mathrm{NPY} C r e /+$ mice (Fig. 4C,D), indicating decreased insulin action in the dentate gyrus of knockout animals (Fig. 4E).

\section{Discussion}

In the present study, we aimed to determine if the loss of IRs in NPY-expressing neurons negatively affected cognitive performance in the MWM, a robust measure of hippocampal-dependent memory performance. Because cognitive performance can be affected by aging, amongst other factors, we tested mice at 6, 12 and 24 months of age. We then examined p-Akt as a measure of insulin signaling in our knockout $\mathrm{IR}^{\text {lox/lox }} ; \mathrm{NPY}$ Cre/+ mouse model. This mouse model has been validated previously and is a robust measure of IR deletion in NPY neurons [38]. This was demonstrated by the authors upon ICV infusion of insulin which caused downstream activation of $\mathrm{p}$-AKT in $\mathrm{IR}^{\text {lox/lox }}$ mice but not IR ${ }^{l o x / l o x}$;NPYCre/+ mice. NPY cells were genetically tagged with a mCherry marker which showed extensive overlap with p-Akt upon ICV insulin infusion in $\mathrm{IR}^{\text {lox } / l o x}$ mice [38].

Consistent with previous research, male $\mathrm{IR}^{\text {lox/lox }} ; \mathrm{NPY}$ Cre/+ mice had significantly increased body weight compared with $\mathrm{IR}^{\text {lox/lox }}$ control mice [38]. This increased body weight may be due to two reasons; a loss of insulin signaling leading to an upregulation of the orexogenic NPY [45] and reduced energy expenditure in $\mathrm{IR}^{l o x / l o x} ; \mathrm{NPY} C r e /+$ mice [38]. In contrast to previous work, no difference in energy intake was observed between genotypes, however, this could be due to differences in study design [38]. Interestingly, differences in body weight by genotype were only observed in male mice at 6 months of age, suggesting that disrupted homeostatic signalling in $\mathrm{IR}^{\text {lox } / \text { lox }} ; \mathrm{NPY}$ Cre/+ mice is reduced in later life. It is unclear why female mice did not show similar body weight differences between genotypes, however it is known that sex plays a role in insulin-dependent regulation of energy homeostasis [25]. Despite sex-differences in body weight at 6 months old, there were no sex differences observed in either genotype during MWM performance, hence the data for male and female were combined. This is in contrast to both rodent and human studies showing that sensitivity to ICV insulin infusion [25] or intranasal insulin [27] affects males and females behavior differently. While this is interesting, our data clearly show that disruption to endogenous insulin signaling is not significantly affected by sex, at least during hippocampal-dependent memory tasks.

In the MWM, IR $\mathrm{IR}^{l o x / l o x}$; $\mathrm{NPY} C r e /+$ mice spent less time in the target quadrant compared to $\mathrm{IR}^{\text {lox } / \text { lox }}$ control mice during the probe trial at 6 and 12 months of age. Importantly, these differences were not a consequence of reduced motivation or locomotor abilities of mice, as all mice showed similar escape latencies during learning of the MWM task. 
A

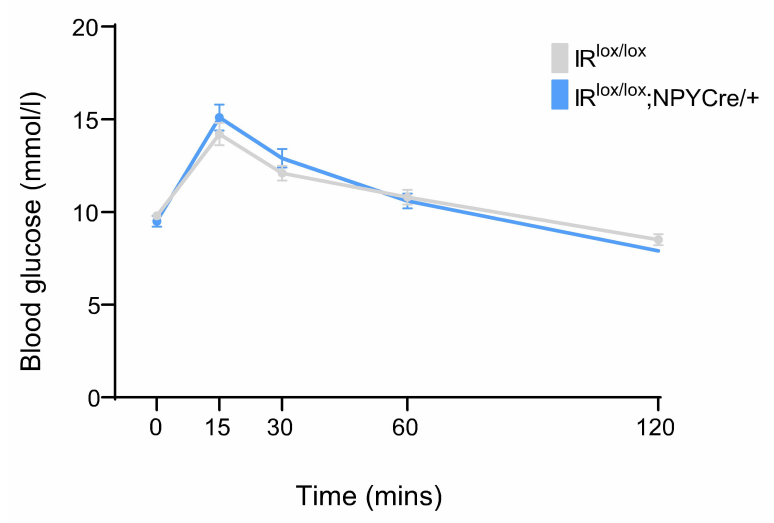

B

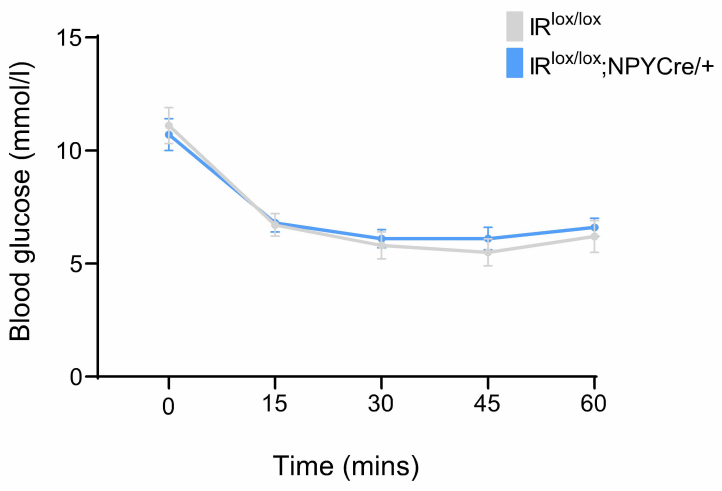

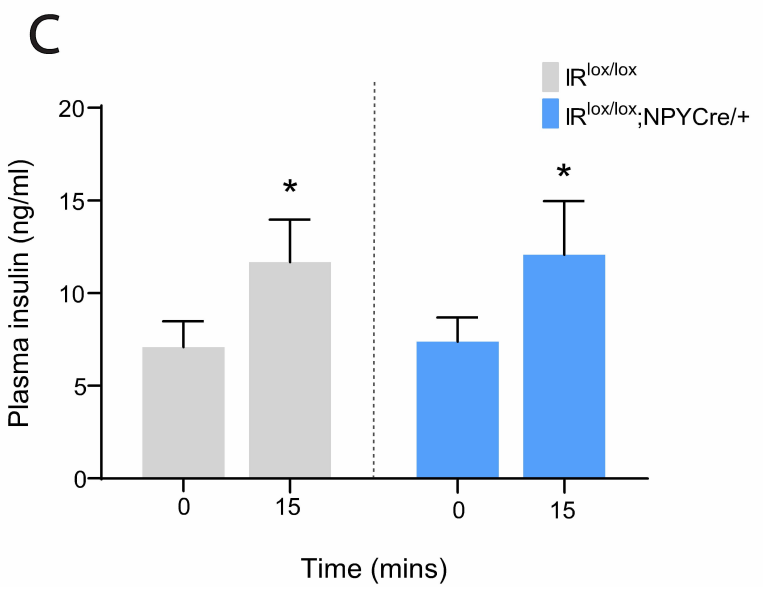

Fig. 3. Blood glucose and insulin. (A) $\mathrm{IR}^{l o x / l o x} ; \mathrm{NPY} C r e /+$ and $\mathrm{IR}^{l o x / l o x}$ mice produced similar glucose tolerance after peripheral glucose injection over 120 minutes. (B) Both groups displayed similar insulin sensitivity after insulin injection over 60 minutes. (C) Plasma insulin levels were not significantly different between $\mathrm{IR}^{l o x / l o x} ; \mathrm{NPYCre} /+$ and $\mathrm{IR}^{l o x} /$ lox mice at baseline or 15 minutes after glucose injection. Values are expressed as mean $\pm \mathrm{SEM}$. ${ }^{*}=p<$ 0.05; by 2-way ANOVA followed by Tukey's honest significance difference (HSD) test. $\mathrm{N}=59 \mathrm{IR}^{\text {lox } / \text { lox }}$ and $56 \mathrm{IR}^{l o x} /$ lox $; \mathrm{NPY} C r e /+$.

Knockout of IRs on NPY neurons did not affect spatial learning during the hidden platform days, therefore this mouse model has specific deficits of spatial memory retrieval during a hippocampal-dependent memory task. These data are consistent with a previous study which found that insulinresistant mice present with hippocampal memory impairments but intact spatial learning on the MWM [13]. Moreover, intrahippocampal insulin administration improves spatial memory performance in the probe test $[13,46]$. Importantly, while these studies show that exogenously administered intra-hippocampal insulin significantly improves cognitive functioning, our results demonstrate that endogenous IR signaling has similarly vital roles in maintaining appropriate cognitive functioning. In line with our work, disrupted or ablated IR signaling is correlated with neuroinflammation and cognitive deficits, including reduced spatial memory acquisition $[47,48]$, while administration of intra-hippocampal PI3K inhibitors impaired memory retrieval [49].

Through the use of our conditional IR $\mathrm{IR}^{\text {lox } / \text { lox }}$;NPYCre/+ knockout mouse model, we conclusively determined that in- sulin's actions in promoting hippocampal function are, at least in part, mediated through NPY cells. The hippocampus is rich in NPY neurons expressing IRs [50-53] and is also crucial in spatial navigation and memory formation $[54,55]$. NPY signalling can enhance stem cell proliferation and neurogenesis via the Y1 receptor within the dentate gyrus [56] and it is possible that insulin signaling may potentiate NPY neuronal activity within the hippocampus to support learning and memory. While these findings do not exclude the contribution of other cell types in mediating hippocampaldependent cognition, they do clearly indicate that IRs on NPY-expressing cells are an instrumental part of a spatial memory circuit.

Interestingly, during the probe test, no difference between $\mathrm{IR}^{\text {lox/lox }}$; NPYCre/+ and $\mathrm{IR}^{\text {lox/lox }}$ controls were observed in the time spent in the target quadrant at 24 months of age. Together, both groups also scored significantly lower when compared to their probe trial at 6 and 12 months of age. Similarly, both groups of mice swam similar path lengths at 6 and 12 months of age, however at 24 months both groups of 

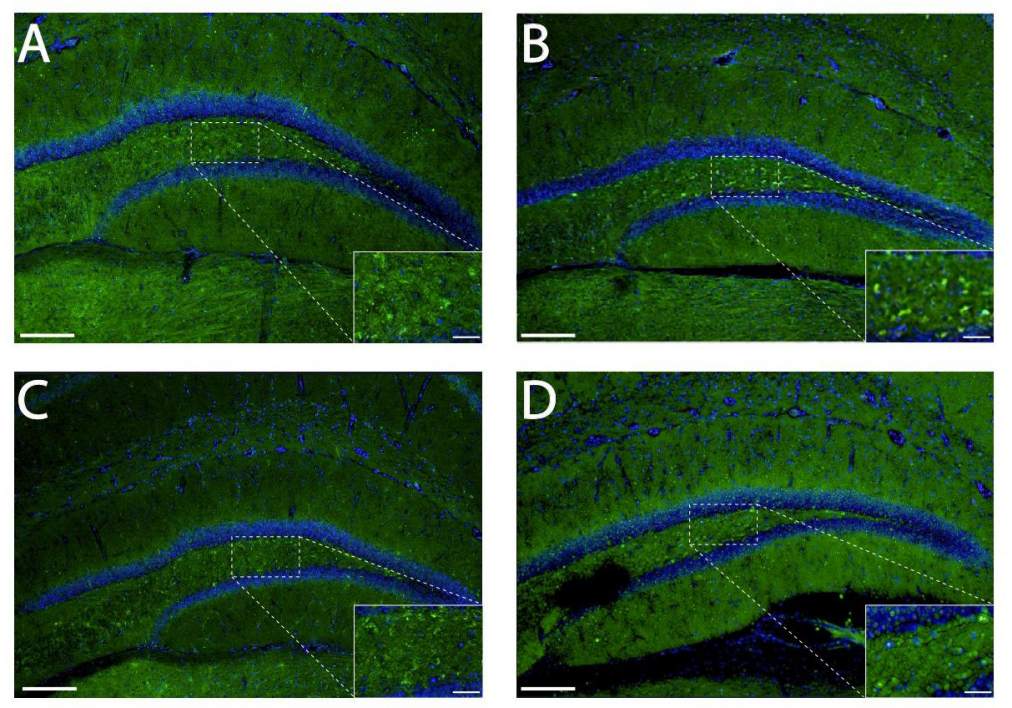

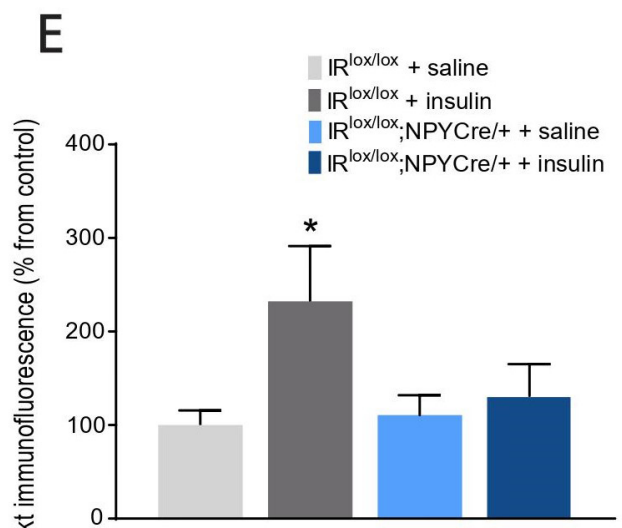

Fig. 4. Representative photomicrographs showing phosphorylated-Akt (green) and DAPI (blue) in the dentate gyrus of the hippocampus. 6 month old $\mathrm{IR}^{l o x / l o x} ; \mathrm{NPY} C r e /+$ or $\mathrm{IR}^{l o x / l o x}$ mice were given a peripheral saline or insulin injection and brain slices were then prepared to examine phosphorylated-Akt (p-Akt). (A) The degree of hippocampal p-Akt in the $\mathrm{IR}^{l o x} /$ lox + saline group was used as a control. (B) P-Akt was significantly increased in $\mathrm{IR}^{l o x / l o x}+$ insulin group, indicating insulin activity. (C) As expected, $\mathrm{IR}^{\text {lox } / \text { lox }}$;NPYCre/+ + saline group displayed p-Akt similar to the $\mathrm{IR}^{l o x / l o x}+$ saline group. (D) $\mathrm{IR}^{\operatorname{lox} / \text { lox }} ; \mathrm{NPY} C r e /++$ insulin group did not display the expected increase in p-Akt. (E) p-Akt immunofluorescent counts were compared between treatment groups as a percentage of control levels (IR ${ }^{l o x} /$ lox + saline) of activity. Values are expressed as mean $\pm \mathrm{SEM}$. ${ }^{*}=p<0.05$; by 1 -way ANOVA followed by Tukey's honest significance difference (HSD) test. Scale bars represent $200 \mu \mathrm{m}$ and $50 \mu \mathrm{m}$ (insets). N = 5/group (10 IR lox/lox and $\left.10 \mathrm{IR}^{\text {lox } / \text { lox }} ; \mathrm{NPY} C r e /+\right)$.

aged mice exhibited decreased path length in the target quadrant, consistent with a floor in performance. These results may be explained due to age-related effects on insulin sensitivity and cognition. Consistent with these findings, other work has found that while young rats show improved performance on the MWM after insulin infusion, aged rats do not show sensitivity to the effects of insulin [46]. This could be due to an age-related decline in IR- $\beta$ immunoreactivity within the hippocampus [57]. Aged animals also exhibit upregulated pro-inflammatory cytokines such as IL-1 $\beta$, TNF$\alpha$ and IL- 6 in the hippocampus, which have been shown to directly impair insulin receptor activity and signaling [58]. These pro-inflammatory cytokines may also contribute to age-related hippocampal insulin resistance [59]. Therefore, our aged $\mathrm{IR}^{l o x / l o x}$ mice may have cognitive decline equivalent to the effect seen with loss of IR on NPY cells due to agedrelated hippocampal insulin insensitivity. To support our MWM data, we identified that $\mathrm{IR}^{\text {lox/lox }}$;NPYCre/+ mice exhibit reduced p-Akt in the dentate gyrus of the hippocampus at 6 months of age, suggesting that these mice exhibit downregulated intra-hippocampal IR signaling. Reduced p-Akt is also seen in states of central insulin resistance [60], which has been implicated with the cognitive decline and cognitive pathologies seen in Alzheimer's disease [61].

There are some limitations in the present study. This work focuses on the role of IR on NPY cells within the hippocampus, however NPY is expressed elsewhere in the brain, such as the hypothalamus [62]. Nevertheless, the present study uses the MWM as a test model, which is known to specifically test hippocampal-based spatial learning and memory [3]. Another consideration is that p-Akt signaling immunohistochemical analysis between $\mathrm{IR}^{l o x / l o x} ; \mathrm{NPY} \mathrm{Cre}^{\mathrm{C}+}$ mice and $\mathrm{IR}^{l o x / l o x}$ mice was only undertaken at 6 months of age. Considering both genotypes of mice exhibited decreased path length and time spent in the target quadrant at 24 months of age, it would be interesting to determine if this memory deficit correlates with impaired p-Akt signaling in both $\mathrm{IR}^{\text {lox } / \text { lox }} ; \mathrm{NPY} C r e /+$ mice and $\mathrm{IR}^{\operatorname{lox} / \text { lox }}$ mice.

\section{Conclusions}

The present study has shown that mice with a tissue specific knockout of IRs in NPY expressing neurons $\left(\mathrm{IR}^{\text {lox/lox}} ; \mathrm{NPY} C r e /+\right)$ demonstrated impaired performance in the probe trial of the MWM compared with control mice at both 6 and 12 months, supporting previous studies that have shown IRs play crucial roles in spatial memory. Importantly, we present novel evidence that these effects are mediated by NPY-expressing cells. Interestingly, no difference between genotypes was observed in aged ( 24 months old) mice. Further research is required to determine age-related physiological changes in IR signaling which modulate spatial memory and learning. Together, this data provides valuable insights into how IR signaling in discrete regions affects cognition, which could have important implications for pathologies related to insulin resistance, such as obesity and Alzheimer's disease. 


\section{Abbreviations}

CNS, Central Nervous System; GTT, Glucose Tolerance Test; IR, Insulin Receptor; ITT, Insulin Tolerance Test; MWM, Morris Water Maze; NPY, Neuropeptide Y.

\section{Author contributions}

DB and HH designed the research study. EG, JT, JG and KA performed the research and analysed the data. EG, CM, $\mathrm{DB}, \mathrm{NR}$ and LZ wrote and reviewed the manuscript. All authors contributed to editorial changes in the manuscript. All authors read and approved the final manuscript.

\section{Ethics approval and consent to participate}

Animals were raised and handled at Australian BioResources Ltd, Moss Vale, NSW, Australia, with genotyping also being performed at this facility. Animals were transferred to University of New South Wales for approved experiments. Experimental procedures were approved by the University of New South Wales Animal Care and Ethics Committee in accordance with the Australian Code of Practice and Use of Animals for Scientific Purposes (ACEC 16/21A).

\section{Acknowledgment}

We thank the anonymous reviewers for the constructive criticism of this article.

\section{Funding}

This work was supported by the Australian Research Council (DE160100088 and DP170100063) and a Ramaciotti Foundation Establishment Grant.

\section{Conflict of interest}

The authors declare no conflict of interest.

\section{References}

[1] Taniguchi CM, Emanuelli B, Kahn CR. Critical nodes in signalling pathways: insights into insulin action. Nature Reviews Molecular Cell Biology. 2006; 7: 85-96.

[2] Convit A. Links between cognitive impairment in insulin resistance: an explanatory model. Neurobiology of Aging. 2005; 26: 31-35.

[3] Bromley-Brits K, Deng Y, Song W. Morris Water Maze Test for Learning and Memory Deficits in Alzheimer\&\#39;s Disease Model Mice. Journal of Visualized Experiments. 2011; e2920.

[4] Stranahan AM, Norman ED, Lee K, Cutler RG, Telljohann RS, Egan JM, et al. Diet-induced insulin resistance impairs hippocampal synaptic plasticity and cognition in middle-aged rats. Hippocampus. 2008; 18: 1085-1088.

[5] Goldbart AD, Row BW, Kheirandish-Gozal L, Cheng Y, Brittian KR, Gozal D. High fat/refined carbohydrate diet enhances the susceptibility to spatial learning deficits in rats exposed to intermittent hypoxia. Brain Research. 2006; 1090: 190-196.

[6] Farr SA, Yamada KA, Butterfield DA, Abdul HM, Xu L, Miller NE, et al. Obesity and Hypertriglyceridemia Produce Cognitive Impairment. Endocrinology. 2008; 149: 2628-2636.

[7] Molteni R, Barnard RJ, Ying Z, Roberts CK, Gómez-Pinilla F. A high-fat, refined sugar diet reduces hippocampal brain-derived neurotrophic factor, neuronal plasticity, and learning. Neuroscience. 2002; 112: 803-814.

[8] Murray AJ, Knight NS, Cochlin LE, McAleese S, Deacon RMJ,
Rawlins JNP, et al. Deterioration of physical performance and cognitive function in rats with short-term high-fat feeding. FASEB Journal. 2009; 23: 4353-4360.

[9] Pistell PJ, Morrison CD, Gupta S, Knight AG, Keller JN, Ingram $\mathrm{DK}$, et al. Cognitive impairment following high fat diet consumption is associated with brain inflammation. Journal of Neuroimmunology. 2010; 219: 25-32.

[10] Messier C, Awad N, Gagnon M. The relationships between atherosclerosis, heart disease, type 2 diabetes and dementia. Neurological Research. 2004; 26: 567-572.

[11] Awad N, Gagnon M, Messier C. The relationship between impaired glucose tolerance, type 2 diabetes, and cognitive function. Journal of Clinical and Experimental Neuropsychology. 2004; 26: 1044-1080.

[12] Watson GS, Craft S. Modulation of memory by insulin and glucose: neuropsychological observations in Alzheimer's disease. European Journal of Pharmacology. 2004; 490: 97-113.

[13] Gladding JM, Abbott KN, Antoniadis CP, Stuart A, Begg DP. The Effect of Intrahippocampal Insulin Infusion on Spatial Cognitive Function and Markers of Neuroinflammation in Diet-induced Obesity. Frontiers in Endocrinology. 2018; 9: 752.

[14] McNay EC, Recknagel AK. Brain insulin signaling: a key component of cognitive processes and a potential basis for cognitive impairment in type 2 diabetes. Neurobiology of Learning and Memory. 2011; 96: 432-442.

[15] Babri S, Badie HG, Khamenei S, Seyedlar MO. Intrahippocampal insulin improves memory in a passive-avoidance task in male wistar rats. Brain and Cognition. 2007; 64: 86-91.

[16] Moosavi M, Naghdi N, Choopani S. Intra CA1 insulin microinjection improves memory consolidation and retrieval. Peptides. 2007; 28: 1029-1034.

[17] Grillo CA, Piroli GG, Lawrence RC, Wrighten SA, Green AJ, Wilson SP, et al. Hippocampal Insulin Resistance Impairs Spatial Learning and Synaptic Plasticity. Diabetes. 2015; 64: 3927-3936.

[18] Burns JM, Honea RA, Vidoni ED, Hutfles LJ, Brooks WM, Swerdlow RH. Insulin is differentially related to cognitive decline and atrophy in Alzheimer's disease and aging. Biochimica Et Biophysica Acta. 2012; 1822: 333-339.

[19] Bingham EM, Hopkins D, Smith D, Pernet A, Hallett W, Reed L, et al. The role of insulin in human brain glucose metabolism: an 18fluoro-deoxyglucose positron emission tomography study. Diabetes. 2002; 51: 3384-3390.

[20] Zhao W, De Felice FG, Fernandez S, Chen H, Lambert MP, Quon $\mathrm{MJ}$, et al. Amyloid beta oligomers induce impairment of neuronal insulin receptors. FASEB Journal. 2008; 22: 246-260.

[21] Zhao WQ, Alkon DL. Role of insulin and insulin receptor in learning and memory. Molecular and Cellular Endocrinology. 2001; 177: $125-134$.

[22] Schiöth HB, Craft S, Brooks SJ, Frey WH, Benedict C. Brain Insulin Signaling and Alzheimer's Disease: Current Evidence and Future Directions. Molecular Neurobiology. 2012; 46: 4-10.

[23] Rasgon N, Jarvik L. Insulin resistance, affective disorders, and Alzheimer's disease: review and hypothesis. The Journals of Gerontology Series a, Biological Sciences and Medical Sciences. 2004; 59: 178-192.

[24] Velazquez R, Tran A, Ishimwe E, Denner L, Dave N, Oddo S, et al. Central insulin dysregulation and energy dyshomeostasis in two mouse models of Alzheimer's disease. Neurobiology of Aging. 2017; 58: 1-13.

[25] Clegg DJ, Riedy CA, Smith KAB, Benoit SC, Woods SC. Differential sensitivity to central leptin and insulin in male and female rats. Diabetes. 2003; 52: 682-687.

[26] Benedict C, Kern W, Schultes B, Born J, Hallschmid M. Differential sensitivity of men and women to anorexigenic and memoryimproving effects of intranasal insulin. The Journal of Clinical Endocrinology and Metabolism. 2008; 93: 1339-1344.

[27] Claxton A, Baker LD, Wilkinson CW, Trittschuh EH, Chapman D, Watson GS, et al. Sex and ApoE genotype differences in treatment response to two doses of intranasal insulin in adults 
with mild cognitive impairment or Alzheimer's disease. Journal of Alzheimer's Disease. 2013; 35: 789-797.

[28] Clegg DJ, Brown LM, Woods SC, Benoit SC. Gonadal Hormones Determine Sensitivity to Central Leptin and Insulin. Diabetes. 2006; 55: 978-987.

[29] Vezzani A, Sperk G, Colmers WF. Neuropeptide Y: emerging evidence for a functional role in seizure modulation. Trends in Neurosciences. 1999; 22: 25-30.

[30] Sørensen AT, Kanter-Schlifke I, Carli M, Balducci C, Noe F, During MJ, et al. NPY gene transfer in the hippocampus attenuates synaptic plasticity and learning. Hippocampus. 2008; 18: 564-574.

[31] Gøtzsche CR, Woldbye DPD. The role of NPY in learning and memory. Neuropeptides. 2016; 55: 79-89.

[32] van den Pol AN. Neuropeptide transmission in brain circuits. Neuron. 2012; 76: 98-115.

[33] Redrobe JP, Dumont Y, Herzog H, Quirion R. Characterization of neuropeptide $\mathrm{Y}, \mathrm{Y}(2)$ receptor knockout mice in two animal models of learning and memory processing. Journal of Molecular Neuroscience. 2004; 22: 159-166.

[34] Agasse F, Bernardino L, Kristiansen H, Christiansen SH, Ferreira $\mathrm{R}$, Silva B, et al. Neuropeptide Y promotes neurogenesis in murine subventricular zone. Stem Cells. 2008; 26: 1636-1645.

[35] Hadad-Ophir O, Albrecht A, Stork O, Richter-Levin G. Amygdala activation and GABAergic gene expression in hippocampal subregions at the interplay of stress and spatial learning. Frontiers in Behavioral Neuroscience. 2014; 8: 3.

[36] Redrobe JP, Dumont Y, St-Pierre JA, Quirion R. Multiple receptors for neuropeptide $\mathrm{Y}$ in the hippocampus: putative roles in seizures and cognition. Brain Research. 2000; 848: 153-166.

[37] Flood JF, Baker ML, Hernandez EN, Morley JE. Modulation of memory processing by neuropeptide $\mathrm{Y}$ varies with brain injection site. Brain Research. 1989; 503: 73-82.

[38] Loh K, Zhang L, Brandon A, Wang Q, Begg D, Qi Y, et al. Insulin controls food intake and energy balance via NPY neurons. Molecular Metabolism. 2017; 6: 574-584.

[39] Brüning JC, Gautam D, Burks DJ, Gillette J, Schubert M, Orban PC, et al. Role of brain insulin receptor in control of body weight and reproduction. Science. 2000; 289: 2122-2125.

[40] Qi Y, Purtell L, Fu M, Lee NJ, Aepler J, Zhang L, et al. Snord116 is critical in the regulation of food intake and body weight. Scientific Reports. 2016; 6: 18614

[41] Vorhees CV, Williams MT. Morris water maze: procedures for assessing spatial and related forms of learning and memory. Nature Protocols. 2006; 1: 848-858.

[42] Manning BD, Cantley LC. AKT/PKB signaling: navigating downstream. Cell. 2007; 129: 1261-1274.

[43] Coffey S, Costacou T, Orchard T, Erkan E. Akt Links Insulin Signaling to Albumin Endocytosis in Proximal Tubule Epithelial Cells. PLoS ONE. 2016; 10: e0140417.

[44] Paxinos G, Franklin KBJ. The mouse brain in stereotaxic coordinates. 2nd edn. Academic Press: San Diego. 2001.

[45] Gelling RW, Morton GJ, Morrison CD, Niswender KD, Myers MG, Rhodes CJ, et al. Insulin action in the brain contributes to glucose lowering during insulin treatment of diabetes. Cell Metabolism. 2006; 3: 67-73.

[46] Adzovic L, Lynn AE, D’Angelo HM, Crockett AM, Kaercher RM, Royer SE, et al. Insulin improves memory and reduces chronic neuroinflammation in the hippocampus of young but not aged brains. Journal of Neuroinflammation. 2015; 12: 63.

[47] Talbot K, Wang H, Kazi H, Han L, Bakshi KP, Stucky A, et al. Demonstrated brain insulin resistance in Alzheimer's disease patients is associated with IGF-1 resistance, IRS-1 dysregulation, and cognitive decline. The Journal of Clinical Investigation. 2012; 122: 1316-1338.

[48] Soto M, Cai W, Konishi M, Kahn CR. Insulin signaling in the hippocampus and amygdala regulates metabolism and neurobehavior. Proceedings of the National Academy of Sciences of the United States of America. 2019; 116: 6379-6384.

[49] Chen X, Garelick MG, Wang H, Lil V, Athos J, Storm DR. PI3 kinase signaling is required for retrieval and extinction of contextual memory. Nature Neuroscience. 2005; 8: 925-931.

[50] Manns JR, Hopkins RO, Squire LR. Semantic memory and the human hippocampus. Neuron. 2003; 38: 127-133.

[51] Ghiasi G, Farshchi A, Pourmotabbed A, Bahrami GR, Nedaee SE Effect of intrahippocampal CA1 injection of insulin on spatial learning and memory deficits in diabetic rats. Journal of Kermanshah University of Medical Sciences. 2011; 15: e69707.

[52] Thorsell A, Michalkiewicz M, Dumont Y, Quirion R, Caberlotto $\mathrm{L}$, Rimondini $\mathrm{R}$, et al. Behavioral insensitivity to restraint stress, absent fear suppression of behavior and impaired spatial learning in transgenic rats with hippocampal neuropeptide $\mathrm{Y}$ overexpression. Proceedings of the National Academy of Sciences of the United States of America. 2000; 97: 12852-12857.

[53] Zhao W, Chen H, Xu H, Moore E, Meiri N, Quon MJ, et al. Brain insulin receptors and spatial memory. Correlated changes in gene expression, tyrosine phosphorylation, and signaling molecules in the hippocampus of water maze trained rats. The Journal of Biological Chemistry. 1999; 274: 34893-34902.

[54] Morris RGM, Garrud P, Rawlins JNP, O’Keefe J. Place navigation impaired in rats with hippocampal lesions. Nature. 1982; 297: 681-683.

[55] Hammond RS, Tull LE, Stackman RW. On the delay-dependent involvement of the hippocampus in object recognition memory. Neurobiology of Learning and Memory. 2004; 82: 26-34.

[56] Gray WP, Scharfman HE. NPY and Hippocampal Neurogenesis, in The NPY Family of Peptides in Immune Disorders, Inflammation, Angiogenesis and Cancer (pp. 201-222). In Zukowska Z, Feuerstein GZ (eds.) Birkhäuser Basel: Basel. 2005.

[57] W, Yoo K, Hwang IK, Choi JH, Lee CH, Park OK, et al. Age-related Changes in the Insulin Receptor $\beta$ in the Gerbil Hippocampus. Neurochemical Research. 2009; 34: 2154-2162.

[58] Biessels GJ, Reagan LP. Hippocampal insulin resistance and cognitive dysfunction. Nature Reviews. Neuroscience. 2015; 16: 660671.

[59] Bettio LEB, Rajendran L, Gil-Mohapel J. The effects of aging in the hippocampus and cognitive decline. Neuroscience and Biobehavioral Reviews. 2017; 79: 66-86.

[60] Huang X, Liu G, Guo J, Su Z. The PI3K/AKT pathway in obesity and type 2 diabetes. International Journal of Biological Sciences. 2018; 14: 1483-1496.

[61] Watson GS, Craft S. The role of insulin resistance in the pathogenesis of Alzheimer's disease: implications for treatment. CNS Drugs. 2003; 17: 27-45.

[62] Gehlert DR, Chronwall BM, Schafer MP, O’Donohue TL. Localization of neuropeptide $\mathrm{Y}$ messenger ribonucleic acid in rat and mouse brian by in situ hybridization. Synapse. 1987; 1: 25-31. 